\title{
Use of Integrative Interactomics for Improvement of Farm Animal Health and Welfare: An Example with Fescue Toxicosis
}

\author{
Ryan S. Mote and Nikolay M. Filipov* \\ Interdisciplinary Toxicology Program, Department of Physiology and Pharmacology, University of Georgia, \\ Athens, GA 30602, USA; ryan.mote25@uga.edu \\ * Correspondence: filipov@uga.edu
}

Received: 8 July 2020; Accepted: 24 September 2020; Published: 1 October 2020

\begin{abstract}
Rapid scientific advances are increasing our understanding of the way complex biological interactions integrate to maintain homeostatic balance and how seemingly small, localized perturbations can lead to systemic effects. The 'omics movement, alongside increased throughput resulting from statistical and computational advances, has transformed our understanding of disease mechanisms and the multi-dimensional interaction between environmental stressors and host physiology through data integration into multi-dimensional analyses, i.e., integrative interactomics. This review focuses on the use of high-throughput technologies in farm animal research, including health- and toxicology-related papers. Although limited, we highlight recent animal agriculture-centered reports from the integrative multi-'omics movement. We provide an example with fescue toxicosis, an economically costly disease affecting grazing livestock, and describe how integrative interactomics can be applied to a disease with a complex pathophysiology in the pursuit of novel treatment and management approaches. We outline how 'omics techniques have been used thus far to understand fescue toxicosis pathophysiology, lay out a framework for the fescue toxicosis integrome, identify some challenges we foresee, and offer possible means for addressing these challenges. Finally, we briefly discuss how the example with fescue toxicosis could be used for other agriculturally important animal health and welfare problems.
\end{abstract}

Keywords: integrative interactomics; integrome; metabolomics; microbiome; tall fescue; Epichloë coenophiala; fescue toxicosis

Key Contribution: This review presents the benefits of integrating multi-'omics data sets (i.e., integrative interactomics) to more comprehensively evaluate farm animal health and adverse toxic insults, while providing the ability to gain molecular insights into systemic responses to numerous internal/external stressors. Based on the fescue toxicosis example herein, we highlight an initial framework for integrative interactomics that allows for in-depth analysis of complex systemic pathophysiology, addition/subtraction of external variables to assess pertinent effects, while steering the field towards developing scalable, translatable, and reproducible integrative interactomics studies.

\section{Introduction}

As world population continues to climb [1], improving production efficiency without sacrificing rigorous quality or safety standards is crucial for sustaining the agricultural supply chain [2]. Significant geopolitical and extreme weather events pose additional negative pressures, while consistent economic growth drives agricultural demand, leading to new challenges for producers and scientists alike [2]. Other extenuating circumstances, like increased risk of a global pandemic in our highly connected 
world, i.e., the Coronavirus disease 2019 (COVID-19) pandemic the world is currently faced with [3], also pose a threat to the global food supply. In the face of these challenges, maintenance of a sustainable, efficient, and adaptable agricultural supply chain is essential. Scientific advances have begun to increase the efficiency of outlining pathophysiological responses by generating high-volume, high-quality datasets quickly, providing novel biological targets for historical and future maladies that may have been missed when using more classical, low-throughput techniques [4]. Thus, recent scientific and technological advances, in conjunction with classical techniques, will continue to improve the ability of the agricultural sector to adapt to both predictable and unforeseen future challenges.

High-throughput technologies are changing the way we investigate complex biological systems by generating large data sets coupled with advanced computational and bioinformatics tools. This includes recent efforts towards combining multi-level data matrices (e.g., genomics, proteomics, metabolomics, etc.). The main focus of the current review is on the application of these technologies to agriculturally important, mycotoxin-induced diseases.

Next-generation sequencing (NGS) can generate high-quality sequencing data regardless of sample origin, increasing our understanding of how genotype influences the ability of organisms to adapt to internal and external stressors. For example, NGS can screen plants for genes associated with agronomic benefits [5]. From a farm animal perspective, NGS has outlined the relationship between ruminant microbes and animal productivity [6,7], allowing investigation of complex ecosystems derived from NGS' culture-independency. Improvements in sequencing technologies have also provided new insights into ecological shifts that occur in the host microbiota after different dietary/treatment regiments [8,9]. Culturomics, a new field centered on cultivating ruminant microorganisms, utilizes NGS and is driven by understanding the biochemical potential of individual microbes [10].

High-resolution mass spectrometry propelled the investigation of the proteome and metabolome [11]. Metabolomics, the study of all low molecular weight compounds within a biological matrix [12], can be used to examine biochemical interactions [13] or to further our understanding of food quality, processing and safety [14]. Much like NGS, advances in the metabolomics computational framework have increased the utility and capacity of metabolomics by improving detection and quantification of both prominent and low abundance metabolites without sacrificing quality [15-18]. Notably, metabolomics scalability has many potential uses; one of the most promising is for biomonitoring of environmental exposures, as suggested for deployed troops [19]. Although computational metabolomics has been proposed for evaluation of the human exposome for a detailed review on the exposome; see: [20], these advances are translatable for improving food safety/quality and, as detailed here, agricultural animal health/wellness.

One important multi-'omics development is computational tools that integrate different 'omics data types (e.g., genome, proteome, metabolome, etc.) into single, interpretable outputs, allowing an evaluation of the integrome through integrative interactomics [21]. Traditionally, interactomics is a broad, yet well-established field focused on mRNA-protein [22] and/or protein-protein [23] interactions within a large spectrum of biological systems and disorders [24-26]. To contrast this view of the interactome, herein we have defined the integrome as the integration of multi-'omics data sets through integrative interactomics, allowing for the description of systemic biological interactions and multi-organ-integrative responses to internal or external variables. The proposed generic framework for the integrome is presented in Figure 1, where grazing animals are used as the example. This initial iteration of the integrome has multiple components. First, molecular characteristics of dietary components are influenced by environmental factors, and a composition of dietary, environmental, and toxin-related exposures determine what animals are exposed to on a daily basis (Figure 1). In response to oral exposures, the animal's enteric physiology shifts to adapt to dietary, environmental and toxicological pressures by altering the microbiome, microbial metabolites, and diet-derived metabolites. The enteric immunoprofile, metabolite/microbe interactions with gut associated lymphoid tissues (GALT), and potential effects on gut wall integrity further effect downstream (patho)physiology. Overall, these enteric physiological shifts dictate what metabolites are present within the gastrointestinal (GI) 
tract and are absorbed into systemic circulation. Further, the enteric immune and enteroendocrine systems signal and influence downstream physiological processes in peripheral tissues (Figure 1). Evaluating metabolites that enter circulation and their fate (e.g., metabolism, receptor interactions, etc.) in the larger biological system is a reflection on how diet and environmental exposures influence downstream host physiology (Figure 1). Finally, microbes and metabolites excreted from the animal, along with grazing and other environmental stresses, may influence, for example in pasture production settings, plant physiology, creating a feedback loop between the plant, dietary/environmental exposures and (patho)physiological changes within the animal (Figure 1). Notably, the excrements (fecal matter, urine) are easily accessible tools and can be used for investigating novel biomarkers of exposure or effect. This framework evaluates systemic, multi-organ responses to dietary and environmental stressors, while considering effects on the entirety of the diet-environment-animal interactions. Overall, technological and computational advances have opened new opportunities to evaluate global, systemic biological interactions. For a detailed review of the computational methods associated with multi-'omics data integration, the mathematical concepts behind these methods, and their application towards toxicological risk assessment, which is outside the scope of the current paper, the readers are directed to the following reviews [27-30].

\section{Integrative Interactomics (Integrome)}

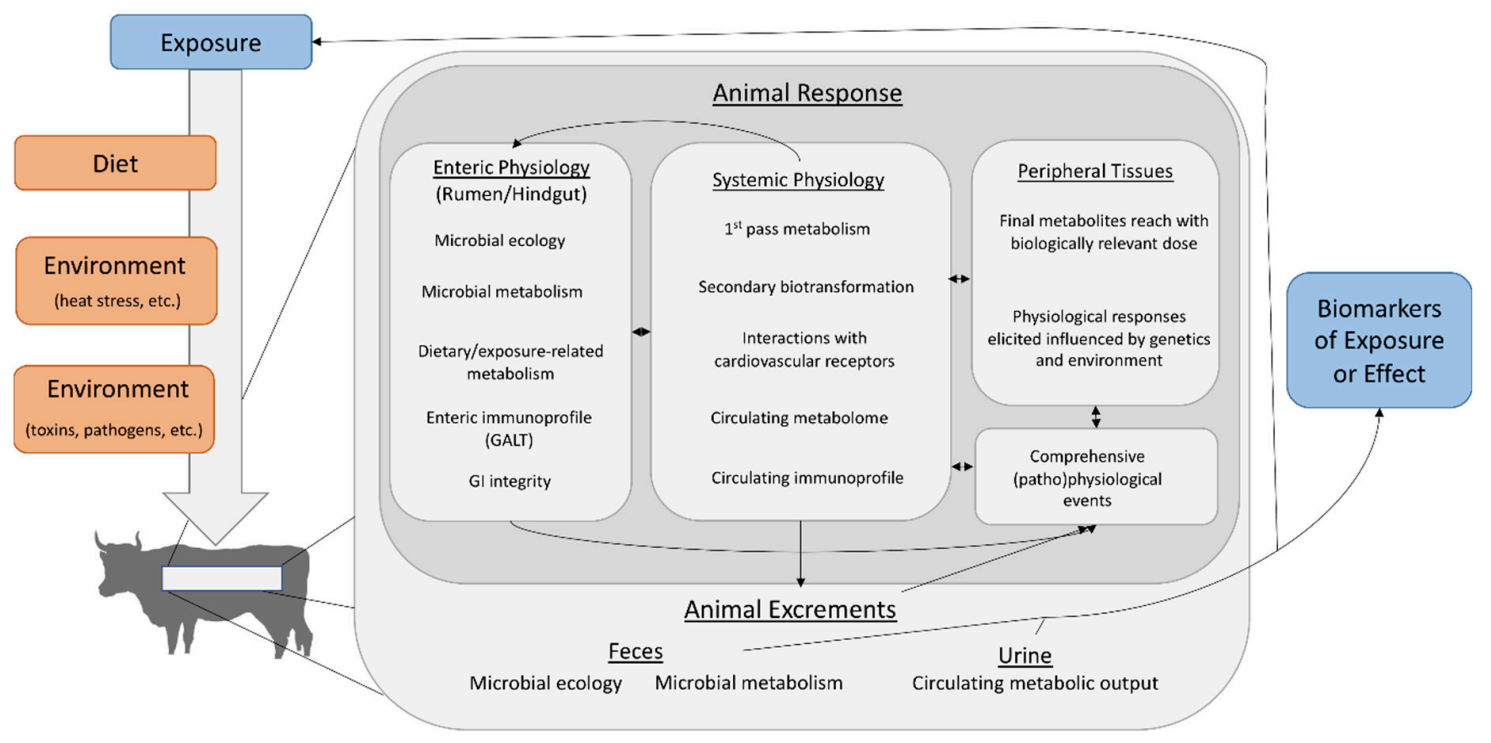

Figure 1. A general, adaptable schematic of the integrome as evaluated through integrative interactomics based on dietary/toxic exposures from an animal agricultural perspective. Animals are exposed to combinations of dietary components, ambient environmental conditions, and external toxicants or pathogens from the environment. Multi-'omics data are collected and integrated within multi-compartment animal responses, which consists of evaluation of enteric (rumen and hindgut herein) and systemic physiological changes, understanding effects on peripheral tissues, and how this results in (patho)physiological effects of interest. Further, animal excrements are an ideal, readily accessible biological matrix that can be utilized to identify biomarker(s) of exposure and/or effect, including those associated with pathophysiological changes. Finally, evaluating how components of the excrements feed back into what animals are exposed to through their diet is also important to the integrome. Overall, this model can help outline global changes that occur in any situation through systematic evaluation of complex biological processes and interactions.

\section{Technological Advances Increase Throughput for Toxicology Screening}

The field of toxicology stands to benefit from integrative interactomics [30]. For example, the Toxicology in the 21st century (Tox21) joint venture in the United States is focused on increasing 
throughput for toxicity screenings (https://tox21.gov/). Drawing conclusions about how individual compounds or mixtures interact within a biological system (e.g., cell, organism) is difficult, but using top-down strategies (i.e., using high-volume global analyses to understand molecular signatures, such as 'omics-based analyses) can provide valuable biological insights missed by bottom-up strategies. Moreover, top-down strategies can evaluate adaptive and pathophysiological responses in plants [31], humans [32], and model organisms [33], which is an important step in understanding the toxicity mechanisms and consequences of environmental exposures. Examples in this regard are low-dose chronic exposures to heavy metal and pesticide mixtures [34,35]. Although these approaches have been previously applied in different contexts, they have specific utility for livestock and large animal physiology/toxicology. Recent work highlighted the bovine genome-microbiome relationship [36], bovine microbiota response to dietary additives [37], and the use of host-microbiota relationship to establish more efficient production systems [38].

Mycotoxin exposures are a major livestock concern. Aflatoxins perturb the immune system [39] and rumen motility [40], while Fusarium mycotoxins (e.g., T-2 toxin) adversely impact livestock reproduction [41]. Reproductive and growth impairments, discussed in detail later, are also associated with Epichloë mycotoxins [42]. Integrative interactomics provides the opportunity to identify novel, mutli-level evidence of direct/indirect mycotoxin effects that, when coupled with traditional methods, can be exploited therapeutically.

\section{Maintaining Animal Productivity and Wellness in Adverse Environments, Toxicity Included}

Improving and maintaining farm animal productivity and wellness is critical. NGS has provided insights into the importance of host genetics on the bovine microbiota $[38,43]$, which seems to be stable after rumen transplant in dairy cattle [44], and the association between microbial genes in the rumen and feed efficiency [45-47]. Further, how the microbiota is influenced by diets/dietary additives has been evaluated [48,49]. As shown recently, the ruminant microbiota is influenced mostly by diet, only partially by the host, and a core microbiota exists across geographies [50,51]. Moreover, rumen microbial communities are influenced by age and environment [52], indicating the developing microbiota could be important for diseases that are either heritable and/or have pre- or postnatal contributing factors. Overall, evaluating the enteric microbiota after exposure to dietary additives or environmental contaminants, as well as after disease onset, is important, since understanding the adaptive microbiota response to these adverse events can help provide a complete picture of the microbiota's role in health and disease.

Metabolomics can also provide important insights into livestock productivity. For example, metabolomics-based methods were used to associate rumen fluid metabolites with feed efficiency [53], assess biochemical variability in bovine milk [54], and identify differences in the bovine milk metabolome during early and late gestation [55]. Metabolomics is used widely to search for biomarker signatures of feed efficiency and disease states in cattle. Livestock metabolomics is not major focus of this review; for an in-depth review, refer to Goldansaz, et al. [56].

How fungal mycotoxins/metabolites influence rumen microbial ecology in animals consuming contaminated feedstuffs is of major interest [57]. While ruminants are considered less susceptible to mycotoxins than monogastrics, ruminant mycotoxicoses do occur and are problematic for animal health and welfare, for a detailed review on ruminant mycotoxicosis, see [58]. Aflatoxin B1 (AB1) is a well-studied mycotoxin; its effects and/or potential biomarkers for exposure in dairy cattle plasma [59,60], as well as rumen fluid and milk [61], have been investigated with metabolomics-based methods. The non-ruminant (porcine) colonic microbiota, namely its functional biodiversity, is impacted by Fusarium mycotoxins [62]; however, despite this, and the utility of NGS and metabolomics in evaluating animal productivity, integrating these separate data sets towards understanding systemic biological responses and the livestock integrome is yet-to-be widely done.

As a whole, animal agriculture would benefit greatly from the development, characterization, and utilization of integrative interactomics-based approaches, and this has been proposed for human health 
as well [63]. Although not in livestock, using an integrative metagenomics and metabolomics approach, $\mathrm{Lu}$, et al. [64] reported that arsenic exposure in drinking water significantly perturbs the host (mouse) microbiota, metabolome, and multiple microbiota-related metabolites. A similar approach was also able to identify a novel relationship between the microbiota, certain metabolites and colorectal cancer, indicating a potential utility of microbial metabolites as diagnostic or therapeutic targets [65]. Finally, Tang, et al. [66] were able to identify microbiota and metabolites that were significantly influenced by diet, indicating that dietary constituents not only influence the gut microbiota, but have systemic effects as well. Similar investigations integrating microbiota and metabolomics data from multiple biological compartments in livestock could provide significant insights into the mechanisms by which dietary, environmental, and mycotoxin exposures influence animal performance.

New data from our lab [67-69], among other recent reports [38,70,71], indicate that developing integrative interactomics-based approaches to complement other, more traditional methods for evaluating the livestock integrome could increase our understanding about the development and adaptive versus pathophysiological responses to one of the costliest diseases to the United States beef industry, fescue toxicosis. The rest of this review will focus on introducing what we currently know about fescue toxicosis development and pathophysiology and how newly generated 'omics data could be integrated to help fill crucial knowledge gaps related to this disease.

\section{Fescue Toxicosis}

\subsection{Tall Fescue and Epichloë Coenophiala}

Tall fescue, Lolium arundinaceum, is a cool season perennial grass that is well adapted to the Southeastern United States, covering approximately 14 million hectares of land. Tall fescue has many compelling agronomic attributes, such as persistence under drought and grazing stresses, resistance to herbivores, nematodes, and insects, and greater potential for nutrient uptake [72]. Ultimately, these attributes give it a competitive advantage over other cultivars and stem from an infection of the plant with the endophytic fungus Epichloë coenophiala [72].

E. coenophiala grows intercellularly and systemically above ground [73] and is vertically transmitted through tall fescue seed heads [74]. Interestingly, the agronomic benefits of E. coenophiala infection appear to be heritable, with both the plant and endophyte genotype influencing offspring persistence [75]. Endophyte-derived bioactive secondary metabolites are considered responsible for the increased persistence of E. coenophiala-infected tall fescue. While some metabolites are beneficial, one group, the ergot alkaloids, have been shown to be detrimental to grazing livestock, inducing the development of fescue toxicosis [76]. Ergot alkaloids are the most abundant class of bioactive secondary metabolites produced by E. coenophiala and are the ones of greatest economic concern in the US [42,77] and worldwide [78,79].

\subsection{Ergot Alkaloids: Presence, Biosynthesis, and Monoaminergic Activities}

The ergot alkaloid profile of tall fescue is variable and consists of lysergic acid derivatives and ergopeptine alkaloids. Both share the same pharmacophore (D-lysergic acid), but classification is derived from functional groups bonded to the primary 8th carbon [80]. Lysergic acid derivatives have a carboxamide functional group, with varying chemical entities bound here used for classification. The ergopeptines have a tripeptide moiety bound to carbon 8 and this is used for ergopeptine nomenclature. For example, the major ergopeptine alkaloid derived from E. coenophiala, ergovaline, has L-alanine, L-proline, and L-valine as constituents, whereas ergotamine, a Claviceps purpurea ergopeptine, has L-alanine, L-proline, and L-phenylalanine as constituents [77].

Studying the activities of ergot alkaloids in biological systems is difficult because the pharmacophore (i.e., the D-lysergic acid backbone) bears structural similarities with dopamine (DA), norepinephrine (NE), and serotonin [5HT; 80]. This allows ergot alkaloids to have systemic 
interactions, eliciting serotonergic, dopaminergic, and adrenergic activities that can influence numerous physiological functions [80].

\subsection{Ergot Alkaloid Metabolism in Ruminant Animals}

The pharmacokinetics of bromocryptine, a synthetic ergot alkaloid, have been extensively studied, but the toxicokinetics of the natural alkaloids of endophyte-infected tall fescue are not well characterized. That said, ergot alkaloids and their metabolites (i.e., lysergic acid) have been detected in the serum after direct injection [81], urine [82,83], bile [83], fluids of the rumen and abomasum [84], subcutaneous fat [85], and liver and kidney tissues [86]; outside the urine, in many instances, the levels are minute. The amount of ergot alkaloids detected decrease through sequential sampling along the GI tract, with one study finding 50-60\% recovered from abomasal contents and $5 \%$ in the feces [87]. Further, as much as $93-96 \%$ of ergot alkaloids are excreted in the urine, although the main metabolite detected in the urine is lysergic acid, suggesting extensive metabolism [83]; lysergic acid is also the main metabolite that crosses gastric tissues [84]. Parent ergopeptine alkaloids are not transported across gastric tissues in vivo and are likely metabolized in the rumen, indicating that downstream processes may contribute to fescue toxicosis development [88]. Overall, these data indicate that ergot alkaloids undergo complex pre-systemic metabolism in the rumen. That said, the effects of ergot alkaloids and their metabolites on microbial populations and microbial metabolism, the potential downstream perturbations caused by this (e.g., microbial-mediated global metabolic effects, immune system effects, etc.), and when the animals transition from an adaptive response to a pathophysiological state need to be investigated; top-down, integrative interactomics-based approaches can help begin this journey.

\subsection{Biomarkers of Ergot Alkaloid Exposure and Effect}

Biomarkers are reproducible, quantifiable biological constructs that result from biological activities and can be used to identify different medical or disease states [89]. Biomarkers need to have high reproducibility across studies or trials while being able to encapsulate the entirety of what it is they are being used to identify. Generally speaking, there are two types of common biomarkers: (1) biomarkers of exposure and (2) biomarkers of effect [90]. Biomarkers of exposure are biological indicators that exposure to a particular substance or compound of interest has occurred, whereas biomarkers of effect indicate that, generally, a pathological effect or disease state is present within a given system. While many biomarkers for fescue toxicosis have been proposed, evidence suggests most of the proposed biomarkers are biomarkers of exposure. For example, it has previously been shown that if ergot alkaloids cross gastric tissues into systemic circulation, they can interact with dopamine receptor subtype 2 (DRD2) receptors on anterior pituitary lactotrophs to decrease serum prolactin [91]. Decreases in serum prolactin have been proposed as a biomarker for ergot alkaloid exposure, but prolactin levels are known to be influenced by photoperiod [92], acute ambient temperature changes [93], and different forms of stress [94,95], which could all lead to reproducibility problems. Detection of total ergot alkaloids in the urine is an accurate, less variable method to assess ergot alkaloid exposure when compared to previous methods, such as decreased serum prolactin $[82,83]$. This is because ninety-four percent of ergot alkaloid excretion occurs in the urine, appearing as early as $12 \mathrm{~h}$ post-exposure, and concentrations are exposure level- and duration-dependent [82]. While urinary alkaloids are of great utility as a sensitive and reproducible biomarker of ergot alkaloid exposure and correlate with reduction in average daily weight gains [ADG; 82], this approach does not speciate individual ergot alkaloids or their metabolites. Speciating ergot alkaloids and metabolites, in plasma, urine, or rumen fluid, might help identify how ruminants metabolize ergot alkaloids and other metabolic processes that may be affected [82,84], which is where integrating multi-'omics data sets will be beneficial.

\subsection{Adverse Effects of Toxic Tall Fescue Grazing and Ergot Alkaloids on Livestock}

Despite notable stand persistence, which sparked initial interest in tall fescue as a pasture cultivar, reports regarding the detrimental impact of tall fescue grazing in livestock began as early 
as the 1940's [96-98]. While cattle grazing tall fescue exhibit numerous signs, such as fescue foot, thermoregulatory impairment, and decreased feed intake, the most economically costly are lowered weight gains and reproductive insufficiencies [99].

Decreased muscle accretion and weight gains are common findings in steers grazing toxic tall fescue. This is a major concern in the beef industry, as these effects can go unnoticed despite their financial impacts [99]. Weight gains are decreased, in part, by lower feed intake and shortened grazing periods; these signs are exacerbated under hot and humid environmental conditions [i.e., heat stress; 99]. The molecular mechanism(s) that lead to decreased food intake are unknown, but current investigations are attempting to elucidate these mechanisms. Considering the dopaminergic and serotonergic activities of ergot alkaloids, it is plausible that one mechanism could be through alterations of gut motility. Strickland, et al. [100] were some of the first to suggest that interaction between ergopeptine alkaloids and enteric receptors [101] could potentially influence gut motility and feed intake. Though the authors noted the interactions between ergot alkaloids and enteric DRD2 receptors, we now know enteric serotonergic activities of ergot alkaloids are another plausible source for altered gut motility induced by toxic tall fescue exposure [101,102]. In support, increases in the baseline tonus of the rumen/reticulum and increased amplitude of reticular contractions follow intravenous infusion of ergovaline, the major ergopeptine in tall fescue [103]. Of note, increased rumen fill that could not be explained by increased dry matter intake, indicate ruminal passage rates may be decreased [104-107] in the absence of changes in energy balance (e.g., energy intake, $\mathrm{O}_{2}$ consumption, $\mathrm{CO}_{2}$ production, heat production, etc.) or feed digestibility [105]. Moreover, voluntary dry matter intake can be inhibited by increases in rumen fill and restricted flow of digesta to the lower gastrointestinal tract [108]. This indicates that, although digestibility and basal metabolic rates may not be affected, changes in gastrointestinal physiology post ergot alkaloid exposure, among other specific metabolic changes (i.e., certain metabolic pathways), could contribute to decreased muscle accretion and weight gains associated with fescue toxicosis through molecular changes. Although these data refer to direct actions of ergot alkaloids, most ergot alkaloids are degraded in the rumen [88]. Therefore, studies investigating the mechanisms behind the decreased weight gains and altered feeding behaviors need to consider: (1) ergot alkaloid metabolites that could directly influence host physiology and (2) indirect effects of ergot alkaloids and their metabolites.

\section{The Case for Integrative Interactomics in Fescue Toxicosis Studies}

Much is known about specific effects of toxic tall fescue grazing and ergot alkaloid exposure in the bovine, but there are still gaps of knowledge about fescue toxicosis pathophysiology. While there is a need for studying specific effects and/or responses, there is also an urgent need to examine the entire system as one integrated set of responses that contribute to decreased animal performance. First, from a plant perspective, evaluating global effects of E. coenophiala infection on important plant physiological characteristics (e.g., rhizosphere, phyllosphere, and endosphere microbiota, the plant metabolome, root exudates, etc.) will provide deeper insights into endophyte-derived molecular changes in the plant that animals are exposed to. Further, top-down strategic approaches may help identify global plant responses, outside of fungal ergot alkaloids, that could contribute to fescue toxicosis pathophysiology. If we assume ergot alkaloids, or the ergot alkaloid pharmacophore, enter the bloodstream and reach target receptors, their receptor promiscuity would result in complex physiological changes. The complexity of studying fescue toxicosis is derived from having to understand the plant-endophyte relationship growing in different geographical regions alongside direct and indirect effects of the entire tall fescue plant, endophyte, and endophyte-derived compounds on the grazing animal. However, an integrative interactomics-based approach would provide multi-level global analysis of different compartments between the plant and animal, providing a breadth of data that begins to address the true complexity of the disease by providing unique integrated information about multi-levels effects of E. coenophiala. When these are coupled with specific analyses of production parameters (i.e., weight gain) and/or physiological measurements (e.g., respiration rates), integrative interactomics will help 
with the identification and prioritization of therapeutic and management strategies of the disease. The complex relationship between the soil, plant, endophyte, and animal is the ideal case for studying the integrome through such systems biology-based approaches. The rest of this review will focus on how systems biology-based approaches have been used previously and demonstrate why integrative interactomics should be used to evaluate the fescue toxicosis integrome and use it to improve disease management alongside current methodologies.

\subsection{Effects of Epichloë Coenophiala Infection on the Plant}

Felitti, et al. [109] performed transcriptome analyses on Neotyphodium (Epichloë) coenophiala, Neotyphodium lolii, and Epichloë festucae, and were able to compare functional changes in expressed sequence tag (EST), a subsequence of cDNA, resulting from growing these fungi on different media, indicating endophyte selection may result in functional in planta changes. Another study found that the endophytes that infect tall fescue plants play a significant role in modulating the rhizosphere and root exudate and how those secretions are modified by soil microbes, indicating a potential utility for endophyte selection to manipulate soil qualities [110]. In support, Rojas, et al. [111] noted that E. coenophiala infection significantly impacts the soil and rhizosphere fungal community population, with similar effects being seen for all endophytes tested. From another perspective, Rasmussen, et al. [112] have published a review summarizing their work, where they've assessed the effects of Neotyphodium lolii infection on the Lolium perenne plant metabolome. One difficulty of this approach is assessing what changes in the plant metabolome may be associated with biotransformation of endophytic metabolites, but Rasmussen and colleagues outlined a potential network of metabolites that are highly integrated between the endophyte and the plant, indicating complex plant-endophyte cross talk [112]. In support, a meta-analysis indicated that Epichloë endophytes promote resistance to insects through certain alkaloids and jasmonic acid pathway metabolites Bastias, et al. [113]. Altogether, these data indicate that endophyte infection significantly alters the rhizosphere and plant microbiota and metabolome, via an incredibly complex plant-endophyte relationship. However, no study has combined plant data in the same study that assesses animal responses to toxic tall fescue grazing.

\subsection{Effects of E. coenophiala-Infected Tall Fescue on the Animal}

\subsubsection{Toxic Tall Fescue Effects along the Bovine Alimentary Tract}

The fate of ergovaline along the enteric tract was previously investigated [88]; it was undetectable in rumen fluid or urine in both in vitro and in vivo experiments. Only lysergic acid was able to cross rumen and omasal tissues, indicating that parent ergopeptine alkaloids likely do not make it into circulation at significant quantities through enteral absorption without undergoing metabolism/biotransformation. That said, one possible route that has yet to be thoroughly explored is possible ergot alkaloid absorption through the lymphatic system. The initial parts of the lymphatic system rely on peristalsis as one mechanism to fill and empty [114]. Considering ergot alkaloids can influence peristalsis through interactions with receptors in the enteric smooth muscle [100-103], ergot alkaloids could be absorbed through the lymphatic networks of the intestinal smooth muscle [115] while also influencing the ability of the initial lymphatic system to fill and empty. However, this possibility needs to be explored further. Overall, these data, combined with Section 4.3., point towards indirect mechanisms through which ergot alkaloids induce fescue toxicosis. Thus, understanding direct, indirect, and systemic effects of toxic tall fescue, ergot alkaloids and their metabolites (e.g., lysergic acid) is crucial to deciphering fescue toxicosis pathogenesis and progression.

To date, limited studies exist examining the effects of E. coenophiala on the bovine microbiota. The fungus Aspergillus terreus was consistently found along the enteric tract in steers that exhibited signs of fescue toxicosis (e.g., fescue foot), indicating enteric fungi may play a role in fescue toxicosis etiology or be useful as a biomarker [116]. Clavine alkaloids, which are ergot alkaloid precursors, appear to have antibiotic-like properties $[117,118]$. Previous work has also shown that ewes inoculated 
with an antibiotic resistant Escherichia coli O157:H7 and fed a high endophyte-infected, versus low endophyte-infected seed shed a greater number of antibiotic resistance genes [119]. Recently, Harlow, et al. [120] investigated rumen bacteria that may degrade ergopeptine alkaloids by evaluating hyper-ammonia producing bacteria $(\mathrm{HAB})$ and tryptophan-utilizing bacteria in vitro; they found that all tested HAB (e.g., Clostridium spp.) degraded ergovaline, with varying degrees of effect. Another recent study [71] assessed the effects of tall fescue seed and red clover isoflavones on global rumen microbial populations in vitro and found limited effects of tall fescue seed on volatile fatty acids. Interestingly, significant effects on bacteria aligned within the Ruminococcaceae, Coriobacteriaceae, and Erysipelotrichaceae families, which is similar to results from our lab where we saw E+ exposure altered the abundances of operational taxonomic units (OTUs) aligned to these families in vivo [67]. Most importantly, we found that toxic tall fescue grazing steers had a unique fecal microbiota structure that could provide insights into easily accessible biomarkers of exposure or effect. In another study, we found similar effects on the fecal microbiota ecology, but also that the fecal microbiota in Angus steers is more easily influenced by heat stress in toxic tall fescue grazing steers versus those on non-toxic tall fescue pastures [69]. This could have multiple origins, one being impaired gut wall integrity. Of note, Alrashedi [121] found increased ruminal Firmicutes and decreased fecal Bacteroidetes in ewes grazing high and medium endophyte-infected tall fescue pastures, with ruminal Prevotella and fecal Coriobacteriaceae operational taxonomic units (OTUs) associating with body weight changes. Finally, Koester, et al. [122] reported significantly decreased bacterial and fungal fecal diversity and richness in Angus cattle that had low tolerance to toxic tall fescue exposure. In this study, the Neocallimastigaceae family was increased in high tolerant steers, whereas the genus Thelebolus was increased in lower tolerance steers. Interestingly, this study also reported farm-to-farm variability in the fecal microbiota of Angus cattle, indicating that putative fecal biomarkers should be systematically evaluated to ensure cross-study validation. Overall, these data affirm that ergot alkaloids/toxic tall fescue significantly alter gut physiology and microbiota along the enteric tract. However, more in vivo analyses need to be performed to understand the importance of the microbiota in fescue toxicosis adaptation/development and whether any of the potentially adverse effects could be targeted therapeutically at gut level.

\subsubsection{Metabolic Effects of Toxic Tall Fescue Grazing}

For a comprehensive review on the overarching physiological changes associated with fescue toxicosis, the authors would direct readers to Strickland, et al. [123]. Briefly, most cellular components of the blood are not affected by toxic tall fescue grazing, but decreased erythrocyte size and hemoglobin content have been reported [124]. One consistent finding in studies analyzing the effects of toxic tall fescue on blood parameters is decreased circulating cholesterol and triglyceride levels [86,124]. Interestingly, bolus injection with ergotamine decreases plasma insulin, while increasing plasma glucagon concentrations within $1 \mathrm{~h}$ post-injection [125]. The impact of ergot alkaloids on plasma cortisol, another metabolism regulating hormone, levels are variable [86,126]. Cattle consuming toxic tall fescue have large variations in circulating norepinephrine and epinephrine levels, which may be associated with altered behavior [127,128]. Tall fescue affects circulating metabolites and hormones and both intra- and extra-hepatic enzyme activities [86], indicating global metabolic effects. Jackson, et al. [129] analyzed specific blood analytes in steers on either high or low endophyte-infected tall fescue pastures, but we first utilized untargeted high-resolution metabolomics to assess global biochemical changes that result from toxic tall fescue grazing [68]. Both plasma and urine metabolomes, namely amino acid and glycerophospholipid metabolism [68], were among the major effects. Interestingly, some metabolic effects are modulated by hot and humid environmental conditions [69], highlighting the complexity of fescue toxicosis pathophysiology. While this work is a starting point, to expand upon these initial results, substantial additional efforts that assess global metabolic changes in response to E. coenophiala infection or exposure, in the fescue plant and grazing animal, are needed. 


\subsubsection{Understanding the Fescue Toxicosis Integrome}

Integrating microbiota and metabolomics data will help outline the relationship between the microbiota, global metabolism, and other parameters such as animal performance. For example, it is well known that shifts in the microbiota influence the presence of microbial metabolites that, in turn, modulate other downstream processes. Toxic tall fescue grazing alters metabolism; however, the microbiome, metabolome and other important physiological parameters have generally been investigated in isolation and not in an integrative manner despite their interconnectedness. The fescue toxicosis integrome is complex; although the plant-endophyte-animal relationship has not been evaluated, we have begun to move in this direction. We successfully integrated the plasma and urine metabolomes with fecal microbiota data to interrogate changes in the microbiota-metabolome relationship that occur after toxic tall fescue exposure [69]. Within this study, the bidirectional relationship between the microbiota and metabolome [130,131], and how this shifts after placement on toxic versus non-toxic tall fescue pastures, was investigated. To do this, we used sparse partial least squares regression (sPLS) to integrate the datasets followed by a differential network analysis to reveal a highly correlated network of fecal OTUs and plasma/urine metabolites. We then identified the OTUs that were correlated with parameters of interest (e.g., average daily weight gains) and found a subnetwork that provides potentially valuable therapeutic targets. As highlighted in Figure 2, understanding the plant-endophyte relationship and how changes in the plant influence bovine physiology through integrating plant and animal data provides a framework for understanding how additional stressors or geographical/cultivar change the disease.

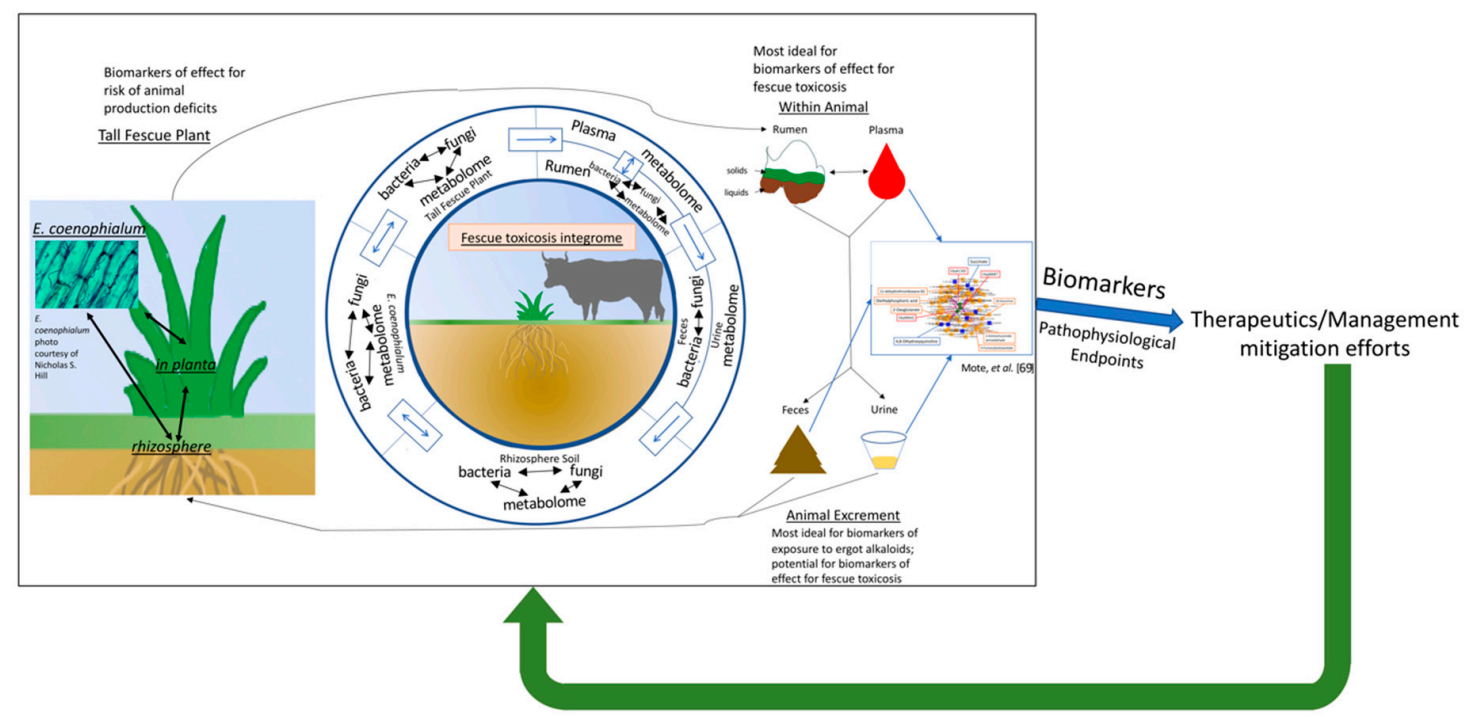

Figure 2. A schematic of the fescue toxicosis integrome. The integrome begins by understanding the complex relationship between the rhizosphere microbiota and metabolome, tall fescue plant microbiota and metabolome, and how these are influenced by the endophyte and grazing stresses. Next, endophyte-related changes are integrated into the animal physiology through microbiota or metabolic changes in the rumen that are reflected by metabolic changes in the plasma prior to microbiota and metabolome effects at the excretion level (feces and urine). The integrome will also allow for understanding the potential for feedback regulation of plant physiology and plant-endophyte relationship by components of the animal excrements, alongside grazing stresses. Of note, changes on the plant side have the potential to be used as biomarkers that have the utility of predicting the risk of animal production deficits of fescue toxicosis. Further, while blood tissues and rumen samples are most suitable for finding biomarkers of effects, animal excrements are ideal for identifying biomarkers of exposure (possibly biomarkers of effects as well) because of their ease of access. One example from our 
previous paper [69] shows how top-down strategies, while centering of global effects, can also identify biological features (i.e., OTUs and metabolic features) that associate with pathophysiological effects (e.g., animal weight gains), highlighting their utility as biomarkers. Biomarkers and pathophysiological endpoints can be used, in conjunction with other methods, to identify potential new and/or improved fescue toxicosis mitigation approaches. They will be then evaluated for their efficacy at multiple levels and the outcomes of the evaluation will inform stakeholders on best ways to improve disease management. Similar approach can be adapted to other conditions, including other economically important toxicoses.

\section{Where Is This Approach for Fescue Toxicosis Research Headed?}

Currently, it is increasingly apparent that indirect, monoamine receptor-independent mechanisms play an important role in fescue toxicosis pathogenesis. To evaluate these, we propose a framework that can be used for interrogating the fescue toxicosis integrome. Understanding the soil-plant-endophyte relationship and how altering this relationship could then influence the toxic fescue grazing beef is a necessary first step (Figure 2). Next, integrating these data with the animal response data (e.g., the rumen/fecal microbiota and metabolomes) will pinpoint some important features that could be targeted therapeutically at the plant level, or as other (i.e., non-ergot alkaloid) potential biomarkers that predict animal production deficit risk (Figure 2). This approach can also point to where pathophysiological changes begin, what other processes may be directly/indirectly influenced within the animal and explain systemic effects of fescue toxicosis (Figure 2). Finally, what the animal is exposed to, as a result of toxic tall fescue grazing will influence host physiology, and ultimately, what that animal excretes. Consequently, grazing animal excrements and grazing stresses will affect the tall fescue plant/endophyte physiology. The integrome considers how these changes, in combination with other environmental factors, influence what the animals are exposed to (Figure 2). Animal biological matrices, such as tissues or blood, have a higher barrier to accessibility, but still provide utility for identifying biomarkers of effects resultant from sensitivity to physiological (whether GI or systemic) changes (Figure 2). The urine or fecal matter provide unique opportunity to identify biomarkers (metabolites or microbes [OTUs]) of exposure to ergot alkaloids and toxic tall fescue, as they are easily accessed (Figure 2). These two readily accessible biological matrices would be ideal for biomarkers of effect as well, if a urine/fecal change is reflective of systematic effects. We used a similar approach to begin investigating the integrome, where we integrated plasma/urine high-resolution metabolomics and fecal bacterial microbiota data to investigate the microbiota-metabolome interactions [69]. Ultimately, we identified one small cluster of metabolites anchored by bacterial OTUs of interest. One Ruminococcaceae, one Clostridium, and one Peptococcaceae candidate genus $r c 4-4$ were highlighted within this network, as they were highly correlated with physiological endpoints of interest (i.e., animal weight gains, urinary ergot alkaloids), plasma (e.g., 4,8-dihydroxyquinoline) and urine (e.g., 18-oxocortisol) metabolites, and were present in the networks under both thermoneutral and hot and humid environmental conditions. Therefore, these metabolites could be useful as biomarkers of a hindgut microbiota associated with signs of fescue toxicosis pathophysiology (i.e., reduced animal productivity) under most ambient environmental conditions [69]. Expanding upon this by integrating the foregut and plant information will be an important step forward towards deciphering the fescue toxicosis integrome.

One of the other most important issues moving forward will be ensuring analytical and computational pipelines are comparable. For example, not only should researchers include sequencing depth and coverage for NGS-based genomics; it was recently shown that differing preprocessing (i.e., Mothur vs QIIME) methods of NGS data can influence the abundance profiles of less common microbes of the rumen [132]. Further, recent comparisons between pipelines leading to amplicon sequence variants (ASVs) and OTUs seem to indicate some differences in specificity between the two, with different OTU-based pipelines producing some non-overlapping spurious OTUs [133]. For metabolomics, differences in analytical platforms, computational methods, and database matching algorithms for metabolomics could also result in metabolic feature variability [134-137]. Finally, while still a less visible, yet budding field, multi-'omics integration methodologies, such as xMWAS [21], 
can vary, and their continual development and improvement will increase consistency. Overall, while this integrative approach will be a great complement to classical techniques and provide additional context for ongoing fescue toxicosis research, much progress still needs to be made to ensure its proper implementation; the current framework could be helpful as an initial guideline.

\section{Applicability of Integrative Interactomics across Agriculture}

While the latter portion of this review focused on developing a framework for using integrative interactomics to help interrogate fescue toxicosis' pathophysiology from a multi-level perspective, this concept is widely applicable across the agricultural sector. The influence of the microbiota on animal production and in numerous disease states, as well as use of metabolomics to identify potential biomarkers of interest, is increasing. For example, Kumar, et al. [138] proposed similar systems-biology based techniques as a potential route for smarter agricultural innovation based on the idea that these techniques help link genotype and phenotype. Shameer, et al. [139] took it a step further by emphasizing using these techniques to develop sustainable agricultural systems, an important and timely endeavor. From an animal perspective, as stated before, these systems biology techniques have been used to assess animal productivity, more so in dairy cattle $[140,141]$. Although no study has comprehensively evaluated what we have termed the integrome, the idea of integrating 'omics data sets has been previously proposed as a potential tool from a meat science perspective [142]. To provide an analogous example of how this could be useful as a complementary approach to classical methods for fescue toxicosis, Johne's Disease, a bovine disease that culminates with weight loss, is used. Recent investigation found that Johne's Disease is associated with profound fecal microbiota dysbiosis [143]. Using this framework could help investigators to detect downstream processes that are affected by gastrointestinal dysbiosis induced by Johne's Disease, select ones that track with wasting and muscle loss, and identify possible new therapeutic target(s). Moreover, it is well known that many mycotoxins are detrimental to livestock productivity, whether through reproductive inefficiencies or by reducing weight gains [144]; this framework is readily applicable towards any mycotoxin, highlighting the translatability of this approach across farm animal exposures and diseases.

\section{Conclusions}

In this review, the case for integrative interactomics as the next step in toxicology and animal agriculture is presented. It should be clear that studying the integrome will be a widely adaptable field moving forward as we continue to improve methodologies. For fescue toxicosis, the proposed framework of the fescue toxicosis integrome is an important step forward. As high-throughput techniques to evaluate different aspects of how toxic tall fescue grazing influences livestock physiology become a mainstay, providing a framework can help align the field towards a cohesive, integrative approach to this complex problem. Taking such an approach will allow identification true fescue toxicosis pathophysiological outcomes, which can help address some study-to-study variations. Using the outcomes from integrative interactomics analyses in conjunction with key production and/or pathophysiology indices will lead to therapeutically valuable target(s) identification and, ultimately, better disease management. Overall, adopting an integrome-based framework, like the one proposed here, has the potential to benefit animal agriculture moving forward.

Funding: The research used as the foundation for this review was funded in part by National Institute of Food and Agriculture (NIFA) Agriculture and Food Research Initiative (AFRI) Grants \#67030-25004 and 67015-31301 to NMF. We would like to thank the Interdisciplinary Toxicology Program, the Department of Physiology and Pharmacology, and the Graduate School of the University of Georgia for partial support to RSM. The support from the Lalita and Raghubir Sharma Distinguished Professorship in Toxicology to NMF is acknowledged.

Conflicts of Interest: The authors declare no conflict of interest. 


\section{References}

1. United Nations, DESA. World Population Prospects 2019; United Nations, Department of Economic and Social Affairs: New York, NY, USA, 2019.

2. USDA OCE. USDA Agricultural Projections to 2028; USDA Office of the Chief Economist Outlook Board: Washington, DC, USA, 2019; p. 108.

3. Li, J.Y.; You, Z.; Wang, Q.; Zhou, Z.J.; Qiu, Y.; Luo, R.; Ge, X.Y. The epidemic of 2019-novel-coronavirus (2019-nCoV) pneumonia and insights for emerging infectious diseases in the future. Microbes Infect. 2020, 22, 80-85. [CrossRef] [PubMed]

4. Capalbo, S.M.; Antle, J.M.; Seavert, C. Next generation data systems and knowledge products to support agricultural producers and science-based policy decision making. Agric. Syst. 2017, 155, 191-199. [CrossRef] [PubMed]

5. Unamba, C.I.; Nag, A.; Sharma, R.K. Next Generation Sequencing Technologies: The Doorway to the Unexplored Genomics of Non-Model Plants. Front. Plant Sci. 2015, 6, 1074. [CrossRef] [PubMed]

6. Matthews, C.; Crispie, F.; Lewis, E.; Reid, M.; O’Toole, P.W.; Cotter, P.D. The rumen microbiome: A crucial consideration when optimising milk and meat production and nitrogen utilisation efficiency. Gut Microbes 2019, 10, 115-132. [CrossRef]

7. Henderson, G.; Cox, F.; Ganesh, S.; Jonker, A.; Young, W.; Global Rumen Census, C.; Janssen, P.H. Rumen microbial community composition varies with diet and host, but a core microbiome is found across a wide geographical range. Sci. Rep. 2015, 5, 14567. [CrossRef]

8. Loor, J.J.; Elolimy, A.A.; McCann, J.C. Dietary impacts on rumen microbiota in beef and dairy production. Anim. Front. 2016, 6, 22-29. [CrossRef]

9. Wolff, S.M.; Ellison, M.J.; Hao, Y.; Cockrum, R.R.; Austin, K.J.; Baraboo, M.; Burch, K.; Lee, H.J.; Maurer, T.; Patil, R.; et al. Diet shifts provoke complex and variable changes in the metabolic networks of the ruminal microbiome. Microbiome 2017, 5, 60. [CrossRef]

10. Zehavi, T.; Probst, M.; Mizrahi, I. Insights Into Culturomics of the Rumen Microbiome. Front. Microbiol. 2018, 9, 1999. [CrossRef]

11. Blum, B.C.; Mousavi, F.; Emili, A. Single-platform 'multi-omic' profiling: Unified mass spectrometry and computational workflows for integrative proteomics-metabolomics analysis. Mol. Omics 2018, 14, 307-319. [CrossRef]

12. Griffiths, W.J. Metabolomics, Metabonomics, and Metabolic Profiling; Royal Society of Chemistry: London, UK, 2008.

13. Bundy, J.G.; Davey, M.P.; Viant, M.R. Environmental metabolomics: A critical review and future perspectives. Metabolomics 2008, 5, 3-21. [CrossRef]

14. Cevallos-Cevallos, J.M.; Reyes-De-Corcuera, J.I.; Etxeberria, E.; Danyluk, M.D.; Rodrick, G.E. Metabolomic analysis in food science: A review. Trends Food Sci. Technol. 2009, 20, 557-566. [CrossRef]

15. Yu, T.; Jones, D.P. Improving peak detection in high-resolution LC/MS metabolomics data using preexisting knowledge and machine learning approach. Bioinformatics 2014, 30, 2941-2948. [CrossRef] [PubMed]

16. Go, Y.M.; Walker, D.I.; Liang, Y.; Uppal, K.; Soltow, Q.A.; Tran, V.; Strobel, F.; Quyyumi, A.A.; Ziegler, T.R.; Pennell, K.D.; et al. Reference Standardization for Mass Spectrometry and High-resolution Metabolomics Applications to Exposome Research. Toxicol. Sci. 2015, 148, 531-543. [CrossRef] [PubMed]

17. Yu, T.; Park, Y.; Johnson, J.M.; Jones, D.P. apLCMS-adaptive processing of high-resolution LC/MS data. Bioinformatics 2009, 25, 1930-1936. [CrossRef] [PubMed]

18. Uppal, K.; Soltow, Q.A.; Strobel, F.H.; Pittard, W.S.; Gernert, K.M.; Yu, T.; Jones, D.P. xMSanalyzer: Automated pipeline for improved feature detection and downstream analysis of large-scale, non-targeted metabolomics data. BMC Bioinform. 2013, 14, 15. [CrossRef]

19. Mallon, T.M.; Krahl, P.K.; Haines, K.M., Jr.; Walker, D.I.; Thatcher, T.; Woeller, C.F.; Thakar, J.; Hopke, P.K.; Gaydos, J.C.; Smith, M.R.; et al. Use of Biomarkers to Assess Environmental Exposures and Health Outcomes in Deployed Troops. J. Occup. Environ. Med. 2019, 61 (Suppl. 12), S1-S4. [CrossRef]

20. Niedzwiecki, M.M.; Walker, D.I.; Vermeulen, R.; Chadeau-Hyam, M.; Jones, D.P.; Miller, G.W. The Exposome: Molecules to Populations. Annu. Rev. Pharmacol. Toxicol. 2019, 59, 107-127. [CrossRef]

21. Uppal, K.; Ma, C.; Go, Y.M.; Jones, D.P.; Wren, J. xMWAS: A data-driven integration and differential network analysis tool. Bioinformatics 2018, 34, 701-702. [CrossRef] 
22. Koster, T.; Marondedze, C.; Meyer, K.; Staiger, D. RNA-Binding Proteins Revisited-The Emerging Arabidopsis mRNA Interactome. Trends Plant Sci. 2017, 22, 512-526. [CrossRef]

23. Maccarrone, G.; Bonfiglio, J.J.; Silberstein, S.; Turck, C.W.; Martins-de-Souza, D. Characterization of a Protein Interactome by Co-Immunoprecipitation and Shotgun Mass Spectrometry. In Multiplex Biomarker Techniques: Methods and Applications; Guest, P.C., Ed.; Springer: New York, NY, USA, 2017; pp. 223-234. [CrossRef]

24. Ghadie, M.A.; Coulombe-Huntington, J.; Xia, Y. Interactome evolution: Insights from genome-wide analyses of protein-protein interactions. Curr. Opin. Struct. Biol. 2018, 50, 42-48. [CrossRef]

25. Shukla, E.; Chauhan, R. Host-HIV-1 Interactome: A Quest for Novel Therapeutic Intervention. Cells 2019, 8, 1155. [CrossRef] [PubMed]

26. Park, D.I.; Turck, C.W. Interactome Studies of Psychiatric Disorders. In Reviews on Biomarker Studies in Psychiatric and Neurodegenerative Disorders; Guest, P.C., Ed.; Springer International Publishing: Cham, Switzerland, 2019; pp. 163-173. [CrossRef]

27. Subramanian, I.; Verma, S.; Kumar, S.; Jere, A.; Anamika, K. Multi-omics Data Integration, Interpretation, and Its Application. Bioinform. Biol. Insights 2020, 14. [CrossRef] [PubMed]

28. Ulfenborg, B. Vertical and horizontal integration of multi-omics data with miodin. BMC Bioinform. 2019, 20, 649. [CrossRef] [PubMed]

29. Bersanelli, M.; Mosca, E.; Remondini, D.; Giampieri, E.; Sala, C.; Castellani, G.; Milanesi, L. Methods for the integration of multi-omics data: Mathematical aspects. BMC Bioinform. 2016, 17, S15. [CrossRef]

30. Canzler, S.; Schor, J.; Busch, W.; Schubert, K.; Rolle-Kampczyk, U.E.; Seitz, H.; Kamp, H.; von Bergen, M.; Buesen, R.; Hackermüller, J. Prospects and challenges of multi-omics data integration in toxicology. Arch. Toxicol. 2020, 94, 371-388. [CrossRef]

31. Zhao, L.; Zhang, H.; White, J.C.; Chen, X.; Li, H.; Qu, X.; Ji, R. Metabolomics reveals that engineered nanomaterial exposure in soil alters both soil rhizosphere metabolite profiles and maize metabolic pathways. Environ. Sci. Nano 2019, 6, 1716-1727. [CrossRef]

32. Walker, D.I.; Lane, K.J.; Liu, K.; Uppal, K.; Patton, A.P.; Durant, J.L.; Jones, D.P.; Brugge, D.; Pennell, K.D. Metabolomic assessment of exposure to near-highway ultrafine particles. J. Expo. Sci. Environ. Epidemiol. 2019, 29, 469-483. [CrossRef]

33. Houten, S.M.; Chen, J.; Belpoggi, F.; Manservisi, F.; Sanchez-Guijo, A.; Wudy, S.A.; Teitelbaum, S.L. Changes in the Metabolome in Response to Low-Dose Exposure to Environmental Chemicals Used in Personal Care Products during Different Windows of Susceptibility. PLoS ONE 2016, 11, e0159919. [CrossRef]

34. Van Meter, R.J.; Glinski, D.A.; Purucker, S.T.; Henderson, W.M. Influence of exposure to pesticide mixtures on the metabolomic profile in post-metamorphic green frogs (Lithobates clamitans). Sci. Total Environ. 2018, 624, 1348-1359. [CrossRef]

35. Grison, S.; Fave, G.; Maillot, M.; Manens, L.; Delissen, O.; Blanchardon, E.; Dublineau, I.; Aigueperse, J.; Bohand, S.; Martin, J.C.; et al. Metabolomics reveals dose effects of low-dose chronic exposure to uranium in rats: Identification of candidate biomarkers in urine samples. Metabolomics 2016, 12, 154. [CrossRef]

36. Golder, H.M.; Thomson, J.M.; Denman, S.E.; McSweeney, C.S.; Lean, I.J. Genetic Markers Are Associated with the Ruminal Microbiome and Metabolome in Grain and Sugar Challenged Dairy Heifers. Front. Genet. 2018, 9, 62. [CrossRef] [PubMed]

37. Wang, B.; Ma, M.P.; Diao, Q.Y.; Tu, Y. Saponin-Induced Shifts in the Rumen Microbiome and Metabolome of Young Cattle. Front. Microbiol. 2019, 10, 356. [CrossRef] [PubMed]

38. Myer, P.R. Bovine Genome-Microbiome Interactions: Metagenomic Frontier for the Selection of Efficient Productivity in Cattle Systems. Msystems 2019, 4, e00103-e00119. [CrossRef]

39. Patterson, D.S.P.; Shreeve, B.J.; Roberts, B.A.; Berrett, S.; Brush, P.J.; Glancy, E.M.; Krogh, P. Effect on calves of barley naturally contaminated with ochratoxin A and groundnut meal contaminated with low concentrations of aflatoxin R1. Res. Vet. Sci. 1981, 31, 213-218. [CrossRef]

40. Cook, W.O.; Richard, J.L.; Osweiler, G.D.; Trampel, D.W. Clinical and pathologic changes in acute bovine aflatoxicosis: Rumen motility and tissue and fluid concentrations of aflatoxins B1 and M1. Am. J. Vet. Res. 1986, 47, 1817-1825.

41. Placinta, C.M.; D’Mello, J.P.F.; Macdonald, A.M.C. A review of worldwide contamination of cereal grains and animal feed with Fusarium mycotoxins. Anim. Feed Sci. Technol. 1999, 78, 21-37. [CrossRef]

42. Klotz, J.L. Activities and Effects of Ergot Alkaloids on Livestock Physiology and Production. Toxins 2015, 7, 2801-2821. [CrossRef] 
43. Li, F.; Li, C.; Chen, Y.; Liu, J.; Zhang, C.; Irving, B.; Fitzsimmons, C.; Plastow, G.; Guan, L.L. Host genetics influence the rumen microbiota and heritable rumen microbial features associate with feed efficiency in cattle. Microbiome 2019, 7, 92. [CrossRef]

44. Weimer, P.J.; Stevenson, D.M.; Mantovani, H.C.; Man, S.L. Host specificity of the ruminal bacterial community in the dairy cow following near-total exchange of ruminal contents. J. Dairy Sci. 2010, 93, 5902-5912. [CrossRef]

45. Delgado, B.; Bach, A.; Guasch, I.; Gonzalez, C.; Elcoso, G.; Pryce, J.E.; Gonzalez-Recio, O. Whole rumen metagenome sequencing allows classifying and predicting feed efficiency and intake levels in cattle. Sci. Rep. 2019, 9, 11. [CrossRef]

46. Lima, J.; Auffret, M.D.; Stewart, R.D.; Dewhurst, R.J.; Duthie, C.A.; Snelling, T.J.; Walker, A.W.; Freeman, T.C.; Watson, M.; Roehe, R. Identification of Rumen Microbial Genes Involved in Pathways Linked to Appetite, Growth, and Feed Conversion Efficiency in Cattle. Front. Genet. 2019, 10, 701. [CrossRef]

47. Jewell, K.A.; McCormick, C.A.; Odt, C.L.; Weimer, P.J.; Suen, G. Ruminal Bacterial Community Composition in Dairy Cows Is Dynamic over the Course of Two Lactations and Correlates with Feed Efficiency. Appl. Environ. Microbiol. 2015, 81, 4697-4710. [CrossRef] [PubMed]

48. Belanche, A.; Kingston-Smith, A.H.; Griffith, G.W.; Newbold, C.J. A Multi-Kingdom Study Reveals the Plasticity of the Rumen Microbiota in Response to a Shift From Non-grazing to Grazing Diets in Sheep. Front. Microbiol. 2019, 10, 122. [CrossRef] [PubMed]

49. Khafipour, E.; Li, S.; Tun, H.M.; Derakhshani, H.; Moossavi, S.; Plaizier, J.C. Effects of grain feeding on microbiota in the digestive tract of cattle. Anim. Front. 2016, 6, 13-19. [CrossRef]

50. Mao, S.; Zhang, M.; Liu, J.; Zhu, W. Characterising the bacterial microbiota across the gastrointestinal tracts of dairy cattle: Membership and potential function. Sci. Rep. 2015, 5, 16116. [CrossRef]

51. de Oliveira, M.N.; Jewell, K.A.; Freitas, F.S.; Benjamin, L.A.; Totola, M.R.; Borges, A.C.; Moraes, C.A.; Suen, G. Characterizing the microbiota across the gastrointestinal tract of a Brazilian Nelore steer. Vet. Microbiol. 2013, 164, 307-314. [CrossRef]

52. O'Hara, E.; Kenny, D.A.; McGovern, E.; Byrne, C.J.; McCabe, M.S.; Guan, L.L.; Waters, S.M. Investigating temporal microbial dynamics in the rumen of beef calves raised on two farms during early life. FEMS Microbiol. Ecol. 2020, 96. [CrossRef]

53. Artegoitia, V.M.; Foote, A.P.; Lewis, R.M.; Freetly, H.C. Rumen Fluid Metabolomics Analysis Associated with Feed Efficiency on Crossbred Steers. Sci. Rep. 2017, 7, 2864. [CrossRef]

54. Boudonck, K.J.; Mitchell, M.W.; Wulff, J.; Ryals, J.A. Characterization of the biochemical variability of bovine milk using metabolomics. Metabolomics 2009, 5, 375-386. [CrossRef]

55. Klein, M.S.; Almstetter, M.F.; Schlamberger, G.; Nurnberger, N.; Dettmer, K.; Oefner, P.J.; Meyer, H.H.; Wiedemann, S.; Gronwald, W. Nuclear magnetic resonance and mass spectrometry-based milk metabolomics in dairy cows during early and late lactation. J. Dairy Sci. 2010, 93, 1539-1550. [CrossRef]

56. Goldansaz, S.A.; Guo, A.C.; Sajed, T.; Steele, M.A.; Plastow, G.S.; Wishart, D.S. Livestock metabolomics and the livestock metabolome: A systematic review. PLoS ONE 2017, 12, e0177675. [CrossRef] [PubMed]

57. Leng, R.A. Biofilm compartmentalisation of the rumen microbiome: Modification of fermentation and degradation of dietary toxins. Anim. Prod. Sci. 2017, 57, 2188-2203. [CrossRef]

58. Gallo, A.; Giuberti, G.; Frisvad, J.C.; Bertuzzi, T.; Nielsen, K.F. Review on Mycotoxin Issues in Ruminants: Occurrence in Forages, Effects of Mycotoxin Ingestion on Health Status and Animal Performance and Practical Strategies to Counteract Their Negative Effects. Toxins 2015, 7, 3057-3111. [CrossRef] [PubMed]

59. Ogunade, I.; Jiang, Y.; Pech Cervantes, A. DI/LC-MS/MS-Based Metabolome Analysis of Plasma Reveals the Effects of Sequestering Agents on the Metabolic Status of Dairy Cows Challenged with Aflatoxin B1. Toxins 2019, 11, 693. [CrossRef]

60. Ogunade, I.; Jiang, Y.; Adeyemi, J.; Oliveira, A.; Vyas, D.; Adesogan, A. Biomarker of Aflatoxin Ingestion: (1)H NMR-Based Plasma Metabolomics of Dairy Cows Fed Aflatoxin B(1) with or without Sequestering Agents. Toxins 2018, 10, 545. [CrossRef]

61. Wang, Q.; Zhang, Y.; Zheng, N.; Guo, L.; Song, X.; Zhao, S.; Wang, J. Biological System Responses of Dairy Cows to Aflatoxin B1 Exposure Revealed with Metabolomic Changes in Multiple Biofluids. Toxins 2019, 11, 77. [CrossRef] 
62. Piotrowska, M.; Slizewska, K.; Nowak, A.; Zielonka, L.; Zakowska, Z.; Gajecka, M.; Gajecki, M. The effect of experimental fusarium mycotoxicosis on microbiota diversity in porcine ascending colon contents. Toxins 2014, 6, 2064-2081. [CrossRef]

63. Shaffer, M.; Armstrong, A.J.S.; Phelan, V.V.; Reisdorph, N.; Lozupone, C.A. Microbiome and metabolome data integration provides insight into health and disease. Transl. Res. 2017, 189, 51-64. [CrossRef]

64. Lu, K.; Abo, R.P.; Schlieper, K.A.; Graffam, M.E.; Levine, S.; Wishnok, J.S.; Swenberg, J.A.; Tannenbaum, S.R.; Fox, J.G. Arsenic exposure perturbs the gut microbiome and its metabolic profile in mice: An integrated metagenomics and metabolomics analysis. Environ. Health Perspect. 2014, 122, 284-291. [CrossRef]

65. Yang, Y.; Misra, B.B.; Liang, L.; Bi, D.; Weng, W.; Wu, W.; Cai, S.; Qin, H.; Goel, A.; Li, X.; et al. Integrated microbiome and metabolome analysis reveals a novel interplay between commensal bacteria and metabolites in colorectal cancer. Theranostics 2019, 9, 4101-4114. [CrossRef]

66. Tang, Z.-Z.; Chen, G.; Hong, Q.; Huang, S.; Smith, H.M.; Shah, R.D.; Scholz, M.; Ferguson, J.F. Multi-Omic Analysis of the Microbiome and Metabolome in Healthy Subjects Reveals Microbiome-Dependent Relationships Between Diet and Metabolites. Front. Genet. 2019, 10, 454. [CrossRef] [PubMed]

67. Mote, R.S.; Hill, N.S.; Skarlupka, J.H.; Turner, Z.B.; Sanders, Z.P.; Jones, D.P.; Suen, G.; Filipov, N.M. Response of Beef Cattle Fecal Microbiota to Grazing on Toxic Tall Fescue. Appl. Environ. Microbiol. 2019, 85, e00032-19. [CrossRef] [PubMed]

68. Mote, R.S.; Hill, N.S.; Uppal, K.; Tran, V.T.; Jones, D.P.; Filipov, N.M. Metabolomics of fescue toxicosis in grazing beef steers. Food Chem. Toxicol. 2017, 105, 285-299. [CrossRef] [PubMed]

69. Mote, R.S.; Hill, N.S.; Skarlupka, J.H.; Tran, V.T.; Walker, D.I.; Turner, Z.B.; Sanders, Z.P.; Jones, D.P.; Suen, G.; Filipov, N.M. Toxic tall fescue grazing increases susceptibility of the Angus steer fecal microbiota and plasma/urine metabolome to environmental effects. Sci. Rep. 2020, 10, 2497. [CrossRef]

70. Melchior, E.A.; Myer, P.R. Fescue toxicosis and its influence on the rumen microbiome: Mitigation of production losses through clover isoflavones. J. Appl. Anim. Res. 2018, 46, 1280-1288. [CrossRef]

71. Melchior, E.A.; Smith, J.K.; Schneider, L.G.; Mulliniks, J.T.; Bates, G.E.; McFarlane, Z.D.; Flythe, M.D.; Klotz, J.L.; Goodman, J.P.; Ji, H.; et al. Effects of red clover isoflavones on tall fescue seed fermentation and microbial populations in vitro. PLOS ONE 2018, 13, e0201866. [CrossRef]

72. Clay, K.; Schardl, C. Evolutionary origins and ecological consequences of endophyte symbiosis with grasses. Am. Nat. 2002, 160 (Suppl. 4), S99-S127. [CrossRef]

73. Christensen, M.J.; Bennett, R.J.; Ansari, H.A.; Koga, H.; Johnson, R.D.; Bryan, G.T.; Simpson, W.R.; Koolaard, J.P.; Nickless, E.M.; Voisey, C.R. Epichloe endophytes grow by intercalary hyphal extension in elongating grass leaves. Fungal Genet. Biol. 2008, 45, 84-93. [CrossRef]

74. Schardl, C.L.; Young, C.A.; Pan, J.; Florea, S.; Takach, J.E.; Panaccione, D.G.; Farman, M.L.; Webb, J.S.; Jaromczyk, J.; Charlton, N.D.; et al. Currencies of mutualisms: Sources of alkaloid genes in vertically transmitted epichloae. Toxins 2013, 5, 1064-1088. [CrossRef]

75. Missaoui, A.; Hill, N. Use of accelerated aging as a surrogate phenotyping approach to improve endophyte survival during storage of tall fescue seed. Field Crop. Res. 2015, 183, 43-49. [CrossRef]

76. Guerre, P. Ergot alkaloids produced by endophytic fungi of the genus Epichloe. Toxins 2015, 7, 773-790. [CrossRef] [PubMed]

77. Young, C.A.; Charlton, N.D.; Takach, J.E.; Swoboda, G.A.; Trammell, M.A.; Huhman, D.V.; Hopkins, A.A. Characterization of Epichloe coenophiala within the US: Are all tall fescue endophytes created equal? Front. Chem. 2014, 2, 95. [CrossRef] [PubMed]

78. Maruo, V.M.; Bracarense, A.P.; Metayer, J.P.; Vilarino, M.; Oswald, I.P.; Pinton, P. Ergot Alkaloids at Doses Close to EU Regulatory Limits Induce Alterations of the Liver and Intestine. Toxins 2018, 10, 183. [CrossRef]

79. Philippe, G. Lolitrem B and Indole Diterpene Alkaloids Produced by Endophytic Fungi of the Genus Epichloe and Their Toxic Effects in Livestock. Toxins 2016, 8, 47. [CrossRef] [PubMed]

80. Berde, B.; Stürmer, E. Introduction to the Pharmacology of Ergot Alkaloids and Related Compounds as a Basis of Their Therapeutic Application; Springer: Berlin/Heidelberg, Germany, 1978; pp. 1-28. [CrossRef]

81. Moubarak, A.S.; Piper, E.L.; Johnson, Z.B.; Flieger, M. HPLC Method for Detection of Ergotamine, Ergosine, and Ergine after Intravenous Injection of a Single Dose. J. Agric. Food Chem. 1996, 44, 146-148. [CrossRef]

82. Hill, N.S.; Thompson, F.N.; Stuedemann, J.A.; Dawe, D.L.; Hiatt, E.E., 3rd. Urinary alkaloid excretion as a diagnostic tool for fescue toxicosis in cattle. J. Vet. Diagn. Investig. 2000, 12, 210-217. [CrossRef] 
83. Stuedemann, J.A.; Hill, N.S.; Thompson, F.N.; Fayrer-Hosken, R.A.; Hay, W.P.; Dawe, D.L.; Seman, D.H.; Martin, S.A. Urinary and biliary excretion of ergot alkaloids from steers that grazed endophyte-infected tall fescue. J. Anim. Sci. 1998, 76, 2146-2154. [CrossRef]

84. Hill, N.S.; Thompson, F.N.; Stuedemann, J.A.; Rottinghaus, G.W.; Ju, H.J.; Dawe, D.L.; Hiatt, E.E., 3rd. Ergot alkaloid transport across ruminant gastric tissues. J. Anim. Sci. 2001, 79, 542-549. [CrossRef]

85. Realini, C.E.; Duckett, S.K.; Hill, N.S.; Hoveland, C.S.; Lyon, B.G.; Sackmann, J.R.; Gillis, M.H. Effect of endophyte type on carcass traits, meat quality, and fatty acid composition of beef cattle grazing tall fescue. $J$. Anim. Sci. 2005, 83, 430-439. [CrossRef]

86. Zbib, N.; Repussard, C.; Tardieu, D.; Priymenko, N.; Domange, C.; Guerre, P. Toxicity of endophyte-infected ryegrass hay containing high ergovaline level in lactating ewes. J. Anim. Sci. 2015, 93, 4098-4109. [CrossRef]

87. Westendorf, M.L.; Mitchell, G.E., Jr.; Tucker, R.E.; Bush, L.P.; Petroski, R.J.; Powell, R.G. In vitro and in vivo ruminal and physiological responses to endophyte-infected tall fescue. J Dairy Sci. 1993, 76, 555-563. [CrossRef]

88. Ayers, A.W.; Hill, N.S.; Rottinghaus, G.E.; Stuedemann, J.A.; Thompson, F.N.; Purinton, P.T.; Seman, D.H.; Dawe, D.L.; Parks, A.H.; Ensley, D. Ruminal Metabolism and Transport of Tall Fescue Ergot Alkaloids. Crop Sci. 2009, 49, 2309-2316. [CrossRef]

89. Strimbu, K.; Tavel, J.A. What are biomarkers? Curr. Opin. HIV AIDS 2010, 5, 463-466. [CrossRef] [PubMed]

90. Mayeux, R. Biomarkers: Potential uses and limitations. NeuroRx 2004, 1, 182-188. [CrossRef] [PubMed]

91. Hurley, W.L.; Convey, E.M.; Leung, K.; Edgerton, L.A.; Hemken, R.W. Bovine prolactin, TSH, T and T concentrations as affected by tall fescue summer toxicosis and temperature. J. Anim. Sci. 1980, 51, 374-379. [CrossRef]

92. Karg, H.; Schams, D. Prolactin release in cattle. J. Reprod. Fertil. 1974, 39, 463-472. [CrossRef]

93. Smith, V.G.; Hacker, R.R.; Brown, R.G. Effect of alterations in ambient temperature on serum prolactin concentration in steers. J. Anim. Sci. 1977, 44, 645-649. [CrossRef]

94. Bryant, G.D.; Linzell, J.L.; Greenwood, F.C. Plasma prolactin in goats measured by radioimmunoassay: The effects of teat stimulation, mating behavior, stress, fasting and of oxytocin, insulin and glucose injections. Hormones 1970, 1, 26-35. [CrossRef]

95. Yayou, K.; Ito, S.; Yamamoto, N.; Kitagawa, S.; Okamura, H. Relationships of stress responses with plasma oxytocin and prolactin in heifer calves. Physiol. Behav. 2010, 99, 362-369. [CrossRef]

96. Cunningham, I. Tall fescue grass is poison for cattle. N. Z. J. Agric. 1948, 77, 519.

97. Cunningham, I.J. A Note on the Cause of Tall Fescue Lameness in Cattle. Aust. Vet. J. 1949, 25, 27-28. [CrossRef]

98. Jacobson, D.R.; Miller, W.M.; Seath, D.M.; Yates, S.G.; Tookey, H.L.; Wolff, I.A. Nature of Fescue Toxicity and Progress toward Identification of the Toxic Entity. J. Dairy Sci. 1963, 46, 416-422. [CrossRef]

99. Paterson, J.; Forcherio, C.; Larson, B.; Samford, M.; Kerley, M. The effects of fescue toxicosis on beef cattle productivity. J. Anim. Sci. 1995, 73, 889-898. [CrossRef] [PubMed]

100. Strickland, J.R.; Oliver, J.W.; Cross, D.L. Fescue toxicosis and its impact on animal agriculture. Vet. Hum. Toxicol. 1993, 35, 454-464. [PubMed]

101. Snider, M.A.; Harmon, D.L.; Klotz, J.L. Pharmacologic assessment of bovine ruminal and mesenteric vascular serotonin receptor populations. J. Anim. Sci. 2018, 96, 1570-1578. [CrossRef] [PubMed]

102. Trotta, R.J.; Harmon, D.L.; Klotz, J.L. Interaction of ergovaline with serotonin receptor 5-HT2A in bovine ruminal and mesenteric vasculature. J. Anim. Sci. 2018, 96, 4912-4922. [CrossRef]

103. McLeay, L.M.; Smith, B.L. Effects of ergotamine and ergovaline on the electromyographic activity of smooth muscle of the reticulum and rumen of sheep. Am. J. Vet. Res. 2006, 67, 707-714. [CrossRef]

104. Foote, A.P.; Kristensen, N.B.; Klotz, J.L.; Kim, D.H.; Koontz, A.F.; McLeod, K.R.; Bush, L.P.; Schrick, F.N.; Harmon, D.L. Ergot alkaloids from endophyte-infected tall fescue decrease reticuloruminal epithelial blood flow and volatile fatty acid absorption from the washed reticulorumen. J. Anim. Sci. 2013, 91, 5366-5378. [CrossRef]

105. Koontz, A.F.; Kim, D.H.; McLeod, K.R.; Klotz, J.L.; Harmon, D.L. Effect of fescue toxicosis on whole body energy and nitrogen balance, in situ degradation and ruminal passage rates in Holstein steers. Anim. Prod. Sci. 2015, 55, 988-998. [CrossRef] 
106. Koontz, A.F.; Bush, L.P.; Klotz, J.L.; McLeod, K.R.; Schrick, F.N.; Harmon, D.L. Evaluation of a ruminally dosed tall fescue seed extract as a model for fescue toxicosis in steers. J. Anim. Sci. 2012, 90, 914-921. [CrossRef]

107. Koontz, A.F.; Kim, D.H.; Foote, A.P.; Bush, L.P.; Klotz, J.L.; McLeod, K.R.; Harmon, D.L. Alteration of fasting heat production during fescue toxicosis in Holstein steers. J. Anim. Sci. 2013, 91, 3881-3888. [CrossRef] [PubMed]

108. Allen, M.S. Physical constraints on voluntary intake of forages by ruminants. J. Anim. Sci. 1996, 74, 3063-3075. [CrossRef] [PubMed]

109. Felitti, S.; Shields, K.; Ramsperger, M.; Tian, P.; Sawbridge, T.; Webster, T.; Logan, E.; Erwin, T.; Forster, J.; Edwards, D.; et al. Transcriptome analysis of Neotyphodium and Epichloe grass endophytes. Fungal Genet. Biol. 2006, 43, 465-475. [CrossRef] [PubMed]

110. Guo, J.; McCulley, R.L.; McNear, D.H., Jr. Tall fescue cultivar and fungal endophyte combinations influence plant growth and root exudate composition. Front. Plant. Sci. 2015, 6, 183. [CrossRef]

111. Rojas, X.; Guo, J.; Leff, J.W.; McNear, D.H., Jr.; Fierer, N.; McCulley, R.L. Infection with a Shoot-Specific Fungal Endophyte (Epichloe) Alters Tall Fescue Soil Microbial Communities. Microb. Ecol. 2016, 72, 197-206. [CrossRef]

112. Rasmussen, S.; Parsons, A.J.; Newman, J.A. Metabolomics analysis of the Lolium perenne-Neotyphodium lolii symbiosis: More than just alkaloids? Phytochem. Rev. 2009, 8, 535-550. [CrossRef]

113. Bastias, D.A.; Martinez-Ghersa, M.A.; Ballare, C.L.; Gundel, P.E. Epichloe Fungal Endophytes and Plant Defenses: Not Just Alkaloids. Trends Plant Sci. 2017, 22, 939-948. [CrossRef]

114. Miller, M.J.; McDole, J.R.; Newberry, R.D. Microanatomy of the intestinal lymphatic system. Ann. N. Y. Acad. Sci. 2010, 1207 (Suppl. 1), E21-E28. [CrossRef]

115. Unthank, J.L.; Bohlen, H.G. Lymphatic pathways and role of valves in lymph propulsion from small intestine. Am. J. Physiol. Gastrointest. Liver Physiol. 1988, 254, G389-G398. [CrossRef]

116. Futrell, M.C.; Farnell, D.R.; Poe, W.E.; Watson, V.H.; Coats, R.E. Fungal Populations in the Rumen Associated with Fescue Toxicosis. J. Environ. Qual. 1974, 3, 140-143. [CrossRef]

117. Eich, E.; Eichberg, D.; Muller, W.E. Clavines. New antibiotics with cytostatic activity. Biochem. Pharmacol. 1984, 33, 523-526. [CrossRef]

118. Eich, E.; Eichberg, D.; Schwarz, G.; Clas, F.; Loos, M. Antimicrobial activitiy of clavines. Arzeimittelforschung 1985, 35, 1760-1762.

119. Looper, M.L.; Edrington, T.S.; Flores, R.; Burke, J.M.; Callaway, T.R.; Aiken, G.E.; Schrick, F.N.; Rosenkrans, C.F., Jr. Influence of dietary endophyte (Neotyphodium coenophialum)-infected tall fescue (Festuca arundinacea) seed on fecal shedding of antibiotic resistance-selected Escherichia coli O157:H7 in ewes. J. Anim. Sci. 2007, 85, 1102-1108. [CrossRef] [PubMed]

120. Harlow, B.E.; Goodman, J.P.; Lynn, B.C.; Flythe, M.D.; Ji, H.; Aiken, G.E. Ruminal tryptophan-utilizing bacteria degrade ergovaline from tall fescue seed extract. J. Anim. Sci. 2017, 95, 980-988. [CrossRef] [PubMed]

121. Alrashedi, S. Effect of Endophyte-Infected Tall Fescue Toxins on Growth Performance and the Microbial Community in the Rumen and Feces in Pregnant Ewes. University of Arkansas. 2017. Available online: http://scholarworks.uark.edu/etd/2532 (accessed on 2 April 2020).

122. Koester, L.; Poole, D.; Serão, N.; Schmitz-Esser, S. Beef cattle that respond differently to fescue toxicosis have distinct gastrointestinal tract microbiota. PLOS ONE 2020, 15, e0229192. [CrossRef]

123. Strickland, J.; Aiken, G.E.; Spiers, D.; Fletcher, L.R.; Oliver, J. Physiological Basis of Fescue Toxicosis. In Tall Fescue for the Twenty-First Century; American Society of Agronomy: Madison, WI, USA, 2009; Volume 53, pp. 203-227. [CrossRef]

124. Oliver, J.W.; Schultze, A.; Rohrbach, B.W.; Fribourg, H.; Ingle, T.; Waller, J. Alterations in hemograms and serum biochemical analytes of steers after prolonged consumption of endophyte-infected tall fescue. J. Anim. Sci. 2000, 78, 1029-1035. [CrossRef]

125. Browning, R., Jr.; Gissendanner, S.J.; Wakefield, T., Jr. Ergotamine alters plasma concentrations of glucagon, insulin, cortisol, and triiodothyronine in cows. J. Anim. Sci. 2000, 78, 690-698. [CrossRef]

126. Coufal-Majewski, S.; Stanford, K.; McAllister, T.; Blakley, B.; McKinnon, J.; Chaves, A.V.; Wang, Y. Impacts of Cereal Ergot in Food Animal Production. Front. Vet. Sci. 2016, 3, 15. [CrossRef] 
127. Schmidt, S.P.; Hoveland, C.S.; Clark, E.M.; Davis, N.D.; Smith, L.A.; Grimes, H.W.; Holliman, J.L. Association of an endophytic fungus with fescue toxicity in steers fed Kentucky 31 tall fescue seed or hay. J. Anim. Sci. 1982, 55, 1259-1263. [CrossRef]

128. Patterson, J.; Looper, M.C.; Williamson, B.; Rosenkrans, C. Effects of fescue cultivar and heat shock protein haplotype on growth and fertility of crossbred beef heifers. Anim. Sci. Ark. Anim. Sci. 2011, 597, 57-59.

129. Jackson, J.J.; Lindemann, M.D.; Boling, J.A.; Matthews, J.C. Summer-Long Grazing of High vs. Low Endophyte (Neotyphodium coenophialum)-Infected Tall Fescue by Growing Beef Steers Results in Distinct Temporal Blood Analyte Response Patterns, with Poor Correlation to Serum Prolactin Levels. Front. Vet. Sci. 2015, 2, 77. [CrossRef] [PubMed]

130. Amar, J. Microbiota-Host Crosstalk: A Bridge Between Cardiovascular Risk Factors, Diet, and Cardiovascular Disease. Am. J. Hypertens. 2018, 31, 941-944. [CrossRef] [PubMed]

131. Goncalves, S.M.; Lagrou, K.; Duarte-Oliveira, C.; Maertens, J.A.; Cunha, C.; Carvalho, A. The microbiome-metabolome crosstalk in the pathogenesis of respiratory fungal diseases. Virulence 2017, 8 , 673-684. [CrossRef] [PubMed]

132. Lopez-Garcia, A.; Pineda-Quiroga, C.; Atxaerandio, R.; Perez, A.; Hernandez, I.; Garcia-Rodriguez, A.; Gonzalez-Recio, O. Comparison of Mothur and QIIME for the Analysis of Rumen Microbiota Composition Based on 16S rRNA Amplicon Sequences. Front. Microbiol. 2018, 9, 3010. [CrossRef] [PubMed]

133. Prodan, A.; Tremaroli, V.; Brolin, H.; Zwinderman, A.H.; Nieuwdorp, M.; Levin, E. Comparing bioinformatic pipelines for microbial 16S rRNA amplicon sequencing. PLoS ONE 2020, 15, e0227434. [CrossRef]

134. Lee, M.Y.; Hu, T. Computational Methods for the Discovery of Metabolic Markers of Complex Traits. Metabolites 2019, 9, 66. [CrossRef]

135. Schrimpe-Rutledge, A.C.; Codreanu, S.G.; Sherrod, S.D.; McLean, J.A. Untargeted Metabolomics Strategies-Challenges and Emerging Directions. J. Am. Soc. Mass Spectrom. 2016, 27, 1897-1905. [CrossRef]

136. Carroll, A.J.; Zhang, P.; Whitehead, L.; Kaines, S.; Tcherkez, G.; Badger, M.R. PhenoMeter: A Metabolome Database Search Tool Using Statistical Similarity Matching of Metabolic Phenotypes for High-Confidence Detection of Functional Links. Front. Bioeng. Biotechnol. 2015, 3, 106. [CrossRef]

137. Longnecker, K.; Futrelle, J.; Coburn, E.; Kido Soule, M.C.; Kujawinski, E.B. Environmental metabolomics: Databases and tools for data analysis. Mar. Chem. 2015, 177, 366-373. [CrossRef]

138. Kumar, A.; Pathak, R.K.; Gupta, S.M.; Gaur, V.S.; Pandey, D. Systems Biology for Smart Crops and Agricultural Innovation: Filling the Gaps between Genotype and Phenotype for Complex Traits Linked with Robust Agricultural Productivity and Sustainability. OMICS 2015, 19, 581-601. [CrossRef]

139. Shameer, K.; Naika, M.B.N.; Shafi, K.M.; Sowdhamini, R. Decoding systems biology of plant stress for sustainable agriculture development and optimized food production. Prog. Biophys. Mol. Biol. 2019, 145, 19-39. [CrossRef] [PubMed]

140. de Menezes, A.B.; Lewis, E.; O’Donovan, M.; O’Neill, B.F.; Clipson, N.; Doyle, E.M. Microbiome analysis of dairy cows fed pasture or total mixed ration diets. FEMS Microbiol. Ecol. 2011, 78, 256-265. [CrossRef] [PubMed]

141. Pitta, D.W.; Kumar, S.; Vecchiarelli, B.; Shirley, D.J.; Bittinger, K.; Baker, L.D.; Ferguson, J.D.; Thomsen, N. Temporal dynamics in the ruminal microbiome of dairy cows during the transition period. J. Anim. Sci. 2014, 92, 4014-4022. [CrossRef] [PubMed]

142. D'Alessandro, A.; Zolla, L. Meat science: From proteomics to integrated omics towards system biology. J. Proteom. 2013, 78, 558-577. [CrossRef] [PubMed]

143. Fecteau, M.E.; Pitta, D.W.; Vecchiarelli, B.; Indugu, N.; Kumar, S.; Gallagher, S.C.; Fyock, T.L.; Sweeney, R.W. Dysbiosis of the Fecal Microbiota in Cattle Infected with Mycobacterium avium subsp. paratuberculosis. PLoS ONE 2016, 11, e0160353. [CrossRef]

144. Iheshiulor, O.O.M.; Esonu, B.O.; Chuwuka, O.K.; Omede, A.A.; Okoli, I.C.; Ogbuewu, I.P. Effects of Mycotoxins in Animal Nutrition: A Review. Asian J. Anim. Sci. 2011, 5, 19-33. [CrossRef]

(C) 2020 by the authors. Licensee MDPI, Basel, Switzerland. This article is an open access article distributed under the terms and conditions of the Creative Commons Attribution (CC BY) license (http://creativecommons.org/licenses/by/4.0/). 